\title{
On a Theme by Williamson: A Stochastic Model for the Evolution of Global Labor Markets since 1830
}

\author{
Fariba Hashemi \\ Swiss Federal Institute of Technology, Lausanne, Switzerland \\ E-mail: Fariba.Hashemi@epfl.ch \\ Received June 14, 2011; revised July 22, 2011; accepted August 1, 2011
}

\begin{abstract}
The cross-sectional distribution of wages has so far been neglected compared to the study of income differences across countries over time. We propose a stochastic model, built on the theory of diffusion processes, to describe the evolution of global labor markets since 1830. The model is applied to empirical data collected by Williamson, in order to describe the level and variation of cross-country wages. The empirical application validates the proposed method.
\end{abstract}

Keywords: Evolution of Global Labor Markets, Spatial Dynamics, Stochastic Analysis

\section{Introduction}

The economics literature is rich with studies which examine wage differentials across countries over time. The dynamics in the cross-sectional distribution of wages have been relatively neglected however. The main objective of this paper is to examine the disequilibrium process of wage adjustment in face of an exogenous shock. We hypothesize that the growth distribution of wages can be generated by a single stochastic process that builds upon the theory of diffusion. A drift-diffusion model is proposed which describes the dynamics of cross-sectional distribution of real wages. The dynamics of the model are governed by the speed of diffusion of knowledge, the mobility of capital and labor, and decline in transportation costs which come along with integration and globalization. An empirical application of the proposed model to the level and variation of real wages using data collected by Williamson between 1830 - 1988 tests the validity of the method.

\section{Theoretical Framework}

In a classic study of global labor markets, Jeffrey Williamson [1] explores the economic convergence of currently industrialized nations and offers a new data base consisting of purchasing-power-parity-adjusted real wage rates for unskilled labor. The new data base has several advantages over the standard GNP estimates, as factor prices generally, and real wages specifically, are likely more suitable measures for the analysis of econo- mic performance and standards of living. This difference becomes significant under conditions of incomplete commodity price equalization. Moreover, labor participation rates differ across space and over time in an environment of migration and differential rates of population growth. Both these considerations hold true with greater strength the farther back in history we look.

This paper explores the dynamics in the evolving distribution of real wages across Williamson's data. Williamson describes his data via four 'regimes'. We explore whether there is an equilibrium distribution of wages in general and to what extent the dynamics of the distribution is 'regime' dependent. We assume a world in which both convergence and divergence forces are at work, with globalization favoring convergence. At the same time, a decline in transportation costs, and faster population growth lead to divergence [2-5]. Consistent with this observation, a model is proposed to describe the fluctuations over time in the density of cross-sectional distribution of real wages. It is hypothesized that these flows follow simple stochastic laws that can be described with five parameters ${ }^{1}$.

Consider a region consisting of a constant number of countries with different levels of wages. The set of wages forms a distribution which evolves over time. Fierce competition in labor markets generates some stationary equilibrium distribution of real wages with a cer-

\footnotetext{
${ }^{1}$ Our study is in the spirit of probabilistic models which study city and firm sizes [6-8]. Our suggestion is that these models could provide interesting insights, if applied to the spatial dynamics of real wages as well.
} 
tain mean and variance, towards which the ensemble of countries considered tend. The equilibrium is a result of tension between counteracting forces of convergence and divergence [9-10]. The drift spread is driven by diminishing returns to capital. A counteracting diffusion spread is at work, driven by bottlenecks in the flow of labor and capital and by random effects, which cause a spread of wages from high density towards lower density. Diffusion of knowledge and learning [11-16] is limited by the presence of obstacles in the form of trade barriers and the like.

Consistent with the above, the following drift-diffusion model is proposed to express the wage adjustment process with noise, describing diffusion of shocks across space:

$$
\frac{\partial f}{\partial t}+\frac{\partial}{\partial s}(\lambda(u-s) f)=\varepsilon \frac{\partial^{2} f}{\partial s^{2}}
$$

where $f$ denotes probability density, $u$ denotes the mean of the stationary equilibrium distribution, $s$ denotes wages, $\lambda$ the wage adjustment rate, and $\varepsilon$ a diffusion parameter ${ }^{2}$.

\section{Empirical Analysis}

The empirical analysis uses Williamson's data [1] which consists of purchasing power parity adjusted real wage rates for unskilled labor recorded from 1830 - 1988. The data is for the following countries ${ }^{3}$ : Argentina, Australia, Belgium, Canada, Denmark, France, Great Britain, Germany, Ireland, Italy, Netherlands, Norway, Spain, Sweden, USA, Brazil and Portugal.

The evidence presented by Williamson suggests that there have been four distinct global labor market 'regimes' since 1830. In this paper, we adopt Williamson's four regimes: (1) 1830-1869, (2) 1870-1913, (3) 19141945, and (4) 1946-1988. The first is associated with early industrialization in Belgium, Denmark, France, Great Britain, Germany, Ireland, Italy, Netherlands, Norway, Spain and Sweden, settlement in Australia, Argentina, Canada and the United States, international migrations, high transport costs on commodity trade, and barriers to trade. The second covers the age of industrialization and free international migration, the Victorian boom amidst an age of imperialism, and a general world boom under free trade and the gold standard. The third covers the two World Wars and the interwar period when world commodity and factor markets break down. The fourth is the post World War II period.

The evolution of the distribution of log of real wages

${ }^{2}$ For an elaboration of this model see [17-22] and the Appendix. across the four time periods has been investigated. Table 1 reports the descriptive statistics for the entire data set, along with the subset used to obtain convergence.

It can be observed that in general, real wages rose sharply, especially in regime 4. Table 1 reports a lower mean wage for Phase 1 as compared with the reported mean wage of Phase 2, Phase 3, and Phase 4. In what follows, we estimate the five model parameters: the initial mean wage $u_{0}$, the initial standard deviation $\sigma_{0}$, the mean wage at stationary equilibrium $u$, the velocity of convergence to stationary equilibrium $\lambda$, and the diffusion parameter $\varepsilon$.

\subsection{Estimation}

The model has been fitted to the log real wage distribution of the four populations as a function of time, using the non-linear least-squares estimation using a two-step procedure. First, the values for $u_{0}, u$ and $\lambda$ were estimated using the first moment of the distribution. In the second step, the values for $\varepsilon$ and $\sigma_{0}$ were computed using the second moment. Tables 2-5 report estimates for the five model parameters, along with the standard errors and t-values for the four phases respectively.

Table 1. Descriptive of the four Phases.

\begin{tabular}{|c|c|c|c|c|c|c|}
\hline & $\mathrm{N}$ & Years & $\begin{array}{l}\text { Min- } \\
\text { imum }\end{array}$ & $\begin{array}{l}\text { Max- } \\
\text { imum }\end{array}$ & Mean & $\begin{array}{l}\text { Std. } \\
\text { Devi- } \\
\text { ation }\end{array}$ \\
\hline Phase 1All data & 369 & 1830-1869 & 3.33 & 4.88 & 4.01 & 0.34 \\
\hline Used: mu & 327 & 1836-1869 & 3.33 & 4.88 & 4.02 & 0.34 \\
\hline Used: sigma & 246 & 1847-1869 & 3.33 & 4.88 & 4.04 & 0.32 \\
\hline Phase 2 All data & 659 & $1870-1913$ & 3.52 & 6.56 & 4.46 & 0.26 \\
\hline Used: mu & 659 & $1870-1913$ & 3.52 & 6.56 & 4.46 & 0.26 \\
\hline Used: sigma & 659 & 1870-1913 & 3.52 & 6.56 & 4.46 & 0.26 \\
\hline Phase 3 All data & 452 & 1914-1945 & 3.66 & 5.60 & 4.80 & 0.27 \\
\hline Used: mu & 52 & $1942-1945$ & 3.66 & 5.60 & 4.80 & 0.39 \\
\hline Used: sigma & 452 & 1914-1945 & 3.66 & 5.60 & 4.80 & 0.27 \\
\hline Phase 4 All data & 640 & 1946-1986 & 4.07 & 6.55 & 5.49 & 0.54 \\
\hline Used: mu & 640 & 1946-1988 & 4.07 & 6.55 & 5.49 & 0.54 \\
\hline Used: sigma & 450 & 1959-1988 & 4.29 & 6.55 & 5.68 & 0.47 \\
\hline
\end{tabular}

${ }^{3}$ Williamson [1] reports data for 11 countries. We are grateful to Williamson for data on the remaining countries, which were collected and received post-publication of [1]. We are also grateful to Mark Hannay for assistance on the empirical analysis section of this paper. 
Table 2. Phase 1 parameter estimates.

\begin{tabular}{cccc}
\hline Parameter & Value & Std Error & t-value \\
\hline$\lambda$ & 0.001 & 0.032 & 0.06 \\
$u$ & 7.09 & 49.87 & 0.14 \\
$u_{0}$ & 3.86 & 0.04 & 83.02 \\
$\sigma_{0}$ & 0.28 & 0.09 & 2.97 \\
$\varepsilon$ & -0.002 & 0.002 & -1.18 \\
\hline
\end{tabular}

Table 3. Phase 2 parameter estimates.

\begin{tabular}{cccc}
\hline Parameter & Value & Std Error & t-value \\
\hline$\lambda$ & 0.03 & 0.005 & 6.31 \\
$u$ & 4.84 & 0.05 & 82.38 \\
$u_{0}$ & 4.09 & 0.01 & 231.79 \\
$\sigma_{0}$ & 0.10 & 0.03 & 2.92 \\
$\varepsilon$ & -0.001 & 0.001 & -0.77 \\
\hline
\end{tabular}

Table 4. Phase 3 parameter estimates.

\begin{tabular}{cccc}
\hline Parameter & Value & Std Error & t-value \\
\hline$\lambda$ & 0.13 & 0.03 & 3.38 \\
$u$ & 4.89 & 0.02 & 172.63 \\
$u_{0}$ & 4.50 & 0.04 & 93.09 \\
$\sigma_{0}$ & -37.31 & 640.56 & -0.05 \\
$\varepsilon$ & 0.03 & 0.06 & 0.57 \\
\hline
\end{tabular}

Table 5. Phase 4 parameter estimates.

\begin{tabular}{cccc}
\hline Parameter & Value & Std Error & t-value \\
\hline$\lambda$ & 0.009 & 0.004 & 1.91 \\
$u$ & 8.63 & 1.63 & 5.28 \\
$u_{0}$ & 4.84 & 0.02 & 168.41 \\
$\sigma_{0}$ & 0.23 & 0.02 & 8.07 \\
$\varepsilon$ & -0.001 & 0.002 & -0.39 \\
\hline
\end{tabular}

One may look at the evolution of actual versus predicted distributions. Figures 1-4 graphically illustrate the evolution of the distribution of real wages over time, superimposed on histograms which describe the time evolution of the distribution of wages in the data across the four Phases. The solid curves in these figures illustrate the distribution of real wages as predicted by the model, and the dotted curves illustrate the distribution of real wages in the data. The vertical axes in these figures denote frequency, and the horizontal axes denote real wages in logarithms.

The following observations can be made concerning our results:
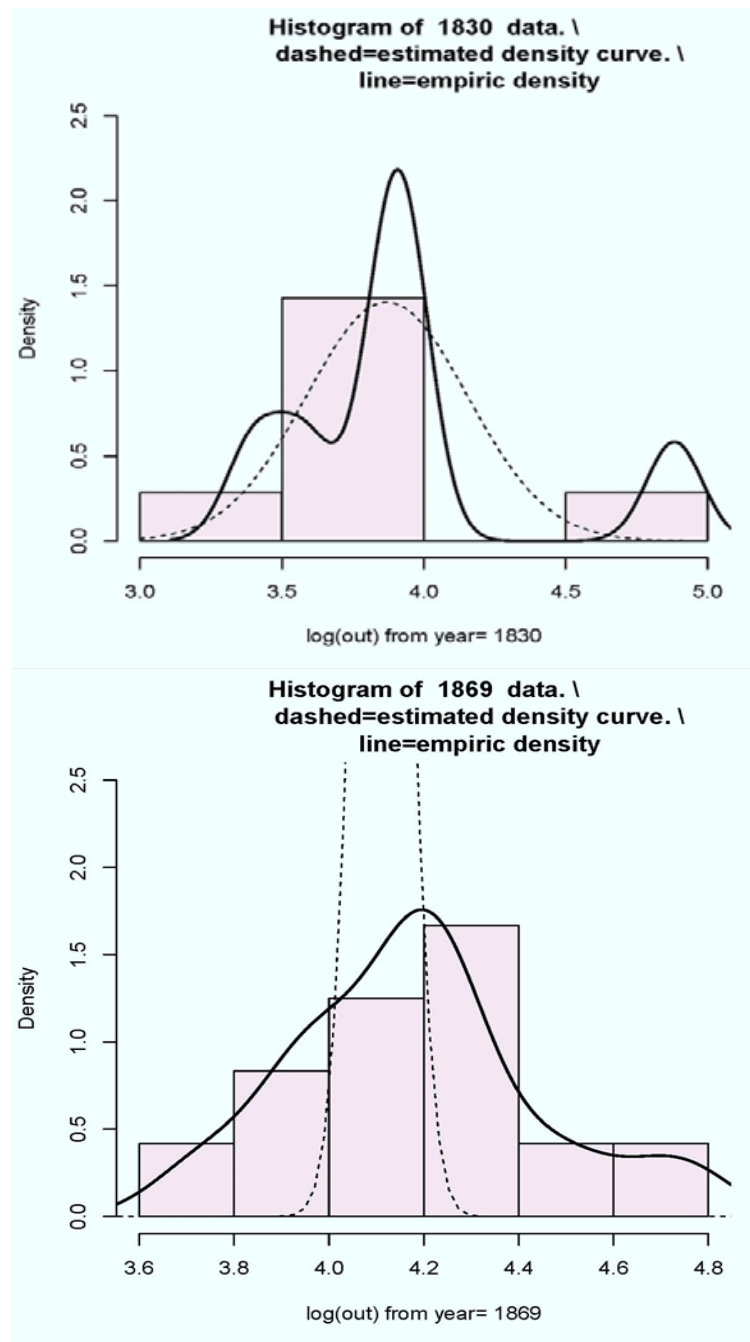

Figure 1. Phase 1 (selected years 1830 and 1869).

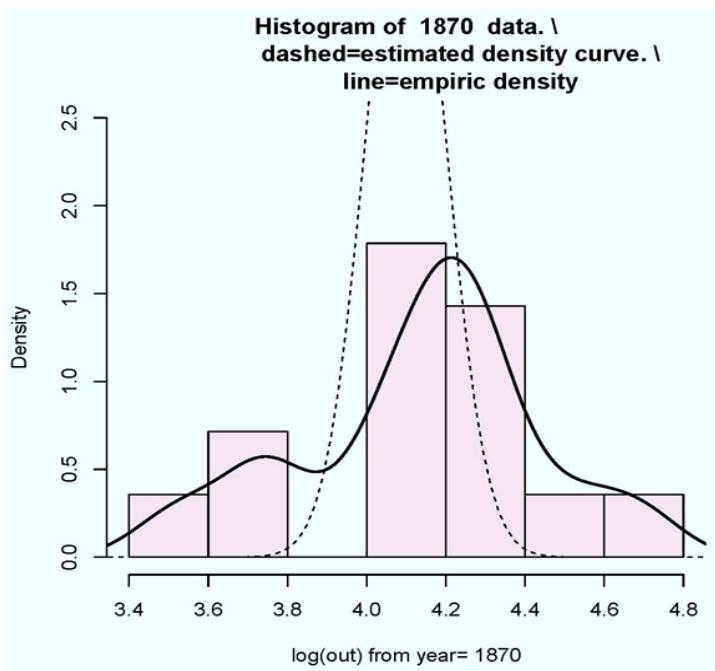




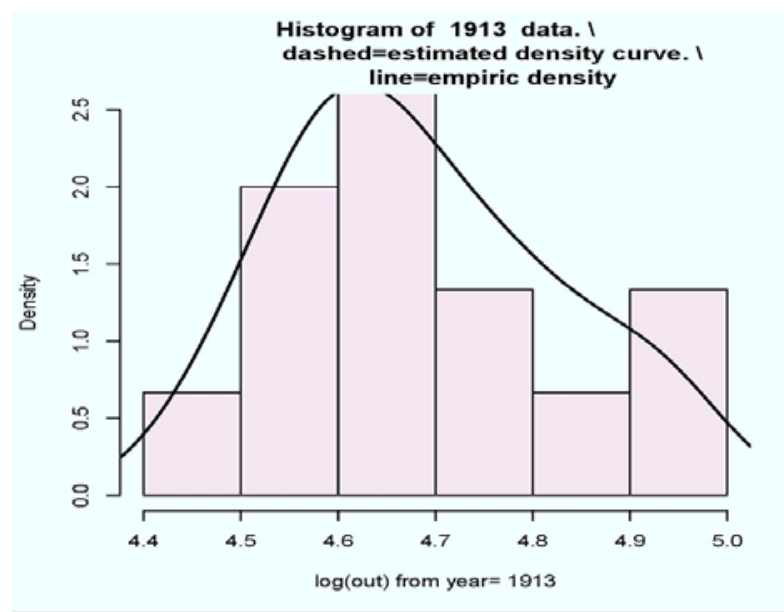

Figure 2. Phase 2 (selected years 1870 and 1913).

1. The mean and variance of all four distributions are clearly evolving, corresponding to our theoretical predictions.

2. The value for the wage adjustment rate $\lambda$ is positive for all four sub-periods and varies from sample to sample as expected.

3. The value for the diffusion parameter $\varepsilon$ is small for all four sub-periods, conforming to our theoretical predictions. The diffusive is: $\lim _{t \rightarrow \infty} \sigma_{t}^{2}=\varepsilon / \lambda$. The results predict that if we start with a normal
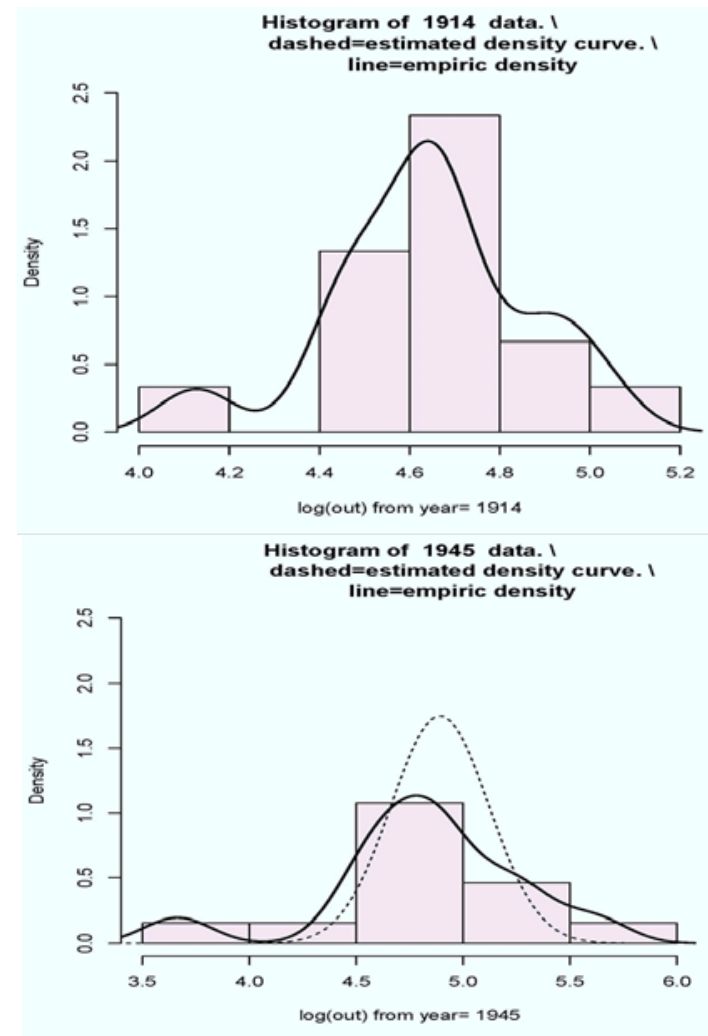

Figure 3. Phase 3 (selected years 1914 and 1945).
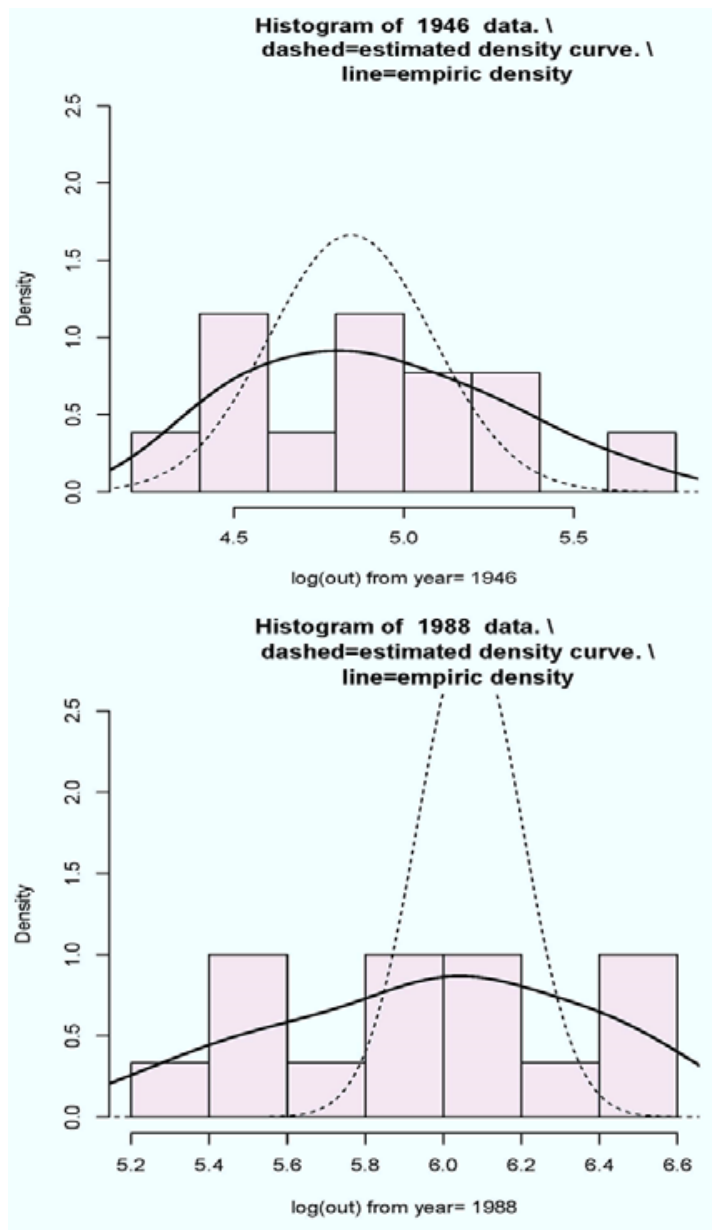

Figure 4. Phase 4 (selected years 1946 and 1988).

distribution and let the model drive the distribution, the distribution variance will tend toward a constant $\varepsilon / \lambda$ and concentrated around a mean $u$ which is largest in order of importance for Phase 4, Phase 1, Phase 3 and Phase 2.

\section{Conclusions}

An empirical application of the proposed model to the dynamics in four subperiods following the classification of Williamson [1] illustrates the applicability of our method. The empirical analysis confirms the results by Williamson and offers some new insights. Like Williamson [23], we find a significant variance in the rate of convergence since the mid-19th century, suggesting that the world economic environment mattered a great deal, and that the forces driving this trend are likely to have had variable quantitative significance across different time periods. Our results illustrate that the methodology proposed in this paper is not without merit, albeit better adapted to certain time periods over others. It can be 
fruitfully extended to shed additional light on historical observations such as those documented by Williamson in $[1,23]$.

\section{References}

[1] J. Williamson, "The Evolution of Global Labour Markets since 1830: Background Evidence and Hypotheses," Explorations in Economic History, Vol. 32, No. 2, 1995, pp. 141- 196. doi:10.1006/exeh.1995.1006

[2] P. Krugman, "Increasing Returns and Economic Geography,” Journal of Political Economy, Vol. 99, No. 3, 1991, pp. 483-499. doi:10.1086/261763

[3] M. Fujita, P. Krugman and T. Mori, "On the Evolution of Hierarchical Urban Systems,” European Economic Review, Vol. 43, No. 2, 1999, pp. 209-251. doi:10.1016/S0014-2921(98)00066-X

[4] D. Levine and S. Modica, "Anti-Malthus: Evolution, Population, and the Maximization of Free Resources," 2011 (Forthcoming).

[5] J. Hirshleifer, "The Dark Side of the Force: Economic Foundations of Conflict Theory,” Cambridge University Press, Cambridge, 2001.

[6] P. Krugman, “The Self-Organizing Economy,” Blackwell Publishers, Oxford, 1996.

[7] R. Axtel, "Zip distribution of US firm sizes," Science, Vol. 293, No. 5536, 2001, pp. 1818-1820. doi:10.1126/science.1062081

[8] F. Hashemi, “A Dynamic Model of Size Distribution of Firms Applied to U.S. Biotechnology and Trucking Industries," Small Business Economics, Vol. 21, No. 1, 2003, pp. 27-36. doi:10.1023/A:1024433203253

[9] R. Lucas, "Trade and the Diffusion of the Industrial Revolution," American Economic Journal: Macroeconomics, Vol. 1, No. 1, 2009, pp. 1-25. doi:10.1257/mac.1.1.1

[10] R. Barro and X. Sala-i-Martin, "Technological Diffusion, Convergence, and Growth,” Journal of Economic Growth, Vol. 2, 1997, p. 126. doi:10.1023/A:1009746629269

[11] D. Fudenberg and D. Levine, "Learning and Equili-

\section{Appendix}

The expression representing the time-development of the distribution is:

$$
f(s, t)=N \mathrm{e}^{\lambda t} \sqrt{\frac{a}{a+\beta}} \mathrm{e}^{-\frac{\left(s-u_{t}\right)^{2}}{2 \sigma_{t}^{2}}}
$$

where brium,” Annual Review of Economics, Vol. 1, 2009, pp. 385-419. doi:10.1146/annurev.economics.050708.142930

[12] D. Levine, “Neuroeconomics,” 2011 (Forthcoming).

[13] A. Alchian, "Uncertainty, Evolution and Economic Theory,” Journal of Political Economy, Vol. 58, 1950, pp. 211-221. doi:10.1086/256940

[14] J. Hirshleifer, "Economics from a Biological Viewpoint," Journal of Law \& Economics, Vol. 20, 1977, pp. 1-52. doi:10.1086/466891

[15] J. Hirshleifer, "Competition, Cooperation, and Conflict in Economics and Biology," American Economic Review, Vol. 68, 1978, pp. 238-243.

[16] D. Levine, "Is Behavioral Economics Doomed? The Ordinary versus the Extraordinary. Open Book Publishers," 2009 (Forthcoming).

[17] F. Hashemi, "An Evolutionary Model of the Size Distribution of Firms," Journal of Evolutionary Economics, Vol. 10, No. 5, 2000, pp. 507-521. doi:10.1007/s001910000048

[18] M.-O. Hongler, R. Filliger and P. Blanchard, "Soluble Models for Dynamics Driven by a Super-Diffusive Noise," Physica, 2006, pp. 301-315.

[19] M-O. Hongler, H. Soner and L. Streit, "Stochastic Control for a Class of Random Evolution Models," Applied Mathematics and Optimization, Vol. 49, 2004, pp. 113121.

[20] O. Besson and G. de Montmollin, "Space-Time Integrated Least Squares: A Time-Marching Approach,” International Journal for Numerical Methods in Fluids, Vol. 44, No. 5, 2004, pp. 525-543. doi:10.1002/fld.655

[21] A. Toda, "Income Dynamics with a Stationary Double Pareto Distribution,” Physical Review, Vol. 83, 2011, pp. 1-4.

[22] F. Hashemi, "East Asian Economic Growth - An Evolutionary Perspective", Journal of Service Science and Management 2011, 4, 280.

[23] J. Williamson, "Globalization, Labor Markets and Policy Backlash in the Past", Journal of Economic Perspectives, Vol. 12, No. 4, 1998, pp. 51-72.

$$
\begin{aligned}
& a=\frac{\sigma_{0}^{2}}{2} \\
& \beta=\frac{\varepsilon}{2 \lambda}\left(\mathrm{e}^{2 \lambda t}-1\right) \\
& u_{t}=E[f]_{t}=u\left(1-\mathrm{e}^{-\lambda t}\right)+u_{0} \mathrm{e}^{-\lambda t} \\
& \sigma_{t}^{2}=\sigma_{0}^{2} \mathrm{e}^{-2 \lambda t}+\frac{\varepsilon}{\lambda}\left(1-\mathrm{e}^{-2 \lambda t}\right)
\end{aligned}
$$

and $N$ is the normalization constant. 